\title{
Evaluation of Deflections of Prestressed Concrete Beams
}

\author{
Min Sook Kim, Young Hak Lee* \\ Kyung Hee University \\ 1732 Deogyeong-daero, Yongin, Korea \\ kimminsook@khu.ac.kr; leeyh@khu.ac.kr*
}

\section{Extended Abstract}

Prestressed concrete beam system could be a good economical alternative to typical reinforced concrete beams because it could provide relative thinner thickness than the conventional concrete beam system. Sherif and Dilger performed fullscale prestressed concrete slab tests and proposed the deflection equation [1]. Chao and Naaman proposed the simplified equation to predict deflection for prestresssed concrete members based on finite element analysis [2]. Abhinav and Valsson studied the behaviour of prestressed beams based on finite element analysis [3]. Amin and Ramez proposed prediction model of long-term deflection for prestressed concrete beams [4]. In this paper, an experimental investigation was carried out to study the flexural behaviour of prestressed concrete beams with eccentricity. Three specimens were manufactured and tested to evaluate the flexural capacity of the prestressed concrete beams considering the eccentricity as a variable. The prestressing force was designed to be the same and each beam had one straight tendon with diameter of $12.7 \mathrm{~mm}$. The design compressive strength of the concrete was $35 \mathrm{MPa}$. The total length and clear span of the specimens were $3.1 \mathrm{~m}$ and $2.7 \mathrm{~m}$, respectively. The sectional width and height of the specimen were $800 \mathrm{~mm}$ and $300 \mathrm{~mm}$, respectively. Boundary condition of all specimens was simply supported. Compared were crack pattern, failure mode, and load-deflection relations in order to evaluate the flexural performance of the specimens. Flexural cracks were first observed in the pure moment zone. As the load was increased, flexural cracks propagated toward the compression zone of the beam. Finally, flexural failure occurred to all the specimens. All the specimens exhibited similar load-deflection responses. On appearance of flexural cracks, the beam stiffness was reduced. The deflection increased substantially with little increase in load. All beams showed ductile behaviour at ultimate. As expected, the maximum load increased as the eccentricity increased. The test results were analysed to propose the nonlinear finite element model taking into account the nonlinearity of concrete. This proposed model is capable of prediction of the deflections considering eccentricity of the tendons. In this model, degenerate shell elements employing a layered discretisation through the thickness were adopted. Analytical and experimental results show good agreement with each other.

\section{Acknowledgment}

This work was supported by the National Research Foundation of Korea (NRF) gran funded by the Korea government (MSIP) (NRF-2013R1A2A2A01067754).

\section{References}

[1] A. G. Sherif and W. H, Dilger, "Analysis and Deflections of Reinforced Concrete Flat Slabs," Canadian Journal for Civil Engineering, vol. 25, pp. 451-466, 1998.

[2] S. Chao and A. E. Naaman, "Simplified Calculation of Short-Term Deflection in Prestressed Two-Way Flat Slabs," ACI Structural Journal, vol. 103, no. 6, pp. 850-856, 2006.

[3] S. K. Abhinav and V. Valsson, "Finite element analysis of prestressed concrete beams," International Journal of Advanced Technology in Civil Engineering, vol. 1, pp. 27-31, 2012.

[4] G. Amin and B. G. Ramez, "Sustainable Serviceability of Structural Concrete: Control of Deflection and Cracking," American Society of Civil Engineers, vol. 140, 2014. 